\title{
A OUVIDORIA COMO INSTRUMENTO DE VALORIZAÇÃO DOS SERVIDORES DO HOSPITAL MUNICIPAL LOURENÇO JORGE
}

\author{
Cristiane Lima Ferreira ${ }^{1}$
}

\begin{abstract}
Resumo
O presente artigo tem como objetivos: apresentar a Ouvidoria do HMLJ - Hospital Municipal Lourenço Jorge como instrumento de gestão e valorização dos colaboradores da instituição; entender a importância de valorizar cada servidor em função do crescimento pessoal e organizacional; e estipular o que pode ser feito para que o colaborador se sinta satisfeito, reconhecido e mais engajado no seu ambiente de trabalho. É vital entender a Ouvidoria como uma ferramenta de grande impacto na organização, não apenas servindo o público externo, mas altamente capacitada para identificar meios de prestigiar e destacar os colaboradores mais comprometidos, empenhados, responsáveis e habilitados, que exercem suas atividades com mais eficiência. Essa prática produz resultados positivos para todos os envolvidos no sistema organizacional, principalmente para os usuários do SUS, que passam a receber os cuidados de profissionais que, valorizados na sua essência como ser humano, sentem-se estimulados a trabalhar mais e melhor, fazendo da instituição não apenas um local de trabalho, mas uma fonte de realização pessoal.
\end{abstract}

Palavras-chave: Ouvidoria. Hospital. Valorização. Colaboradores. Gestão. Resultado.

1 Graduada no Curso de Pedagogia da UERJ. Pós-graduada em Gestão e Docência do Ensino Superior. (cristiane. ferreira@smsdc.rio.rj.gov.br) 


\begin{abstract}
The purposes of this article are: to present the HMLJ - Hospital Municipal Lourenço Jorge Ombudsman as an instrument for managing and valuing employees of the institution; understand the importance of valuing each server in terms of personal and organizational growth; and stipulate what can be done to make the employee feel satisfied, recognized and more engaged in their work environment. It is vital to understand the Ombudsman's Office as a tool that has a great impact on the organization, not only serving the external public, but also highly qualified to identify ways to honor and highlight the most committed, responsible and capable employees, who carry out their activities more efficiently. This practice produces positive results for all those involved in the organizational system, especially SUS patients, who receive the care of professionals valued in their essence as a human being, a value that encourages them to work more and better, making the institution not only a place of work, but a source of personal fulfillment.
\end{abstract}

Keywords: Ombudsman. Hospital. Appreciation. Contributors. Management. Result. 


\section{INTRODUÇÃO}

Conduzir e gerenciar uma pequena ou média equipe de trabalho requer muita atenção a diversas questões para que a gestão de pessoas seja realizada com êxito. Todavia, maior desafio representa administrar um grande hospital público, referência em emergência numa grande capital, que possui em seu quadro funcionários concursados em diversas categorias.O reconhecimento e a valorização pela qualificação e competência do colaborador integram, de forma fundamental, o processo de motivação e crescimento de uma equipe. Sabe-se que motivação é uma força interna e pessoal que, bem trabalhada pela gestão, impulsiona e incentiva. Entretanto, em alguns casos, a própria estabilidade do servidor público impede que ele ouse mais ou se motive.

Um profissional motivado demonstra dedicação e empenho maiores e mais relevantes, seja na execução de tarefas, na gestão e até mesmo no convívio com os demais no ambiente de trabalho. Políticas que visam esse objetivo devem ser adotadas e colocadas em prática por gestores e organizações. Pensando em quebrar paradigmas, a Ouvidoria do Hospital Municipal Lourenço Jorge decidiu apostar na valorização do servidor público, tornando-o mais positivamente competitivo e satisfeito com seu trabalho.

O Hospital Municipal Lourenço Jorge, do município do Rio de Janeiro, acolhe uma média mensal de 10 mil atendimentos nas suas diversas especialidades médicas (Cirurgia Bucomaxilofacial, Clínica Médica, Cirurgia Geral, Cirurgia Vascular, Pediatria e Ortopedia).

Com relação à natureza dos atendimentos, pode-se afirmar que ela se divide nos três polos de assistência, sendo eles: SPA (Serviço de Pronto Atendimento), Emergência/Politrauma e Serviço Ambulatorial. O SPA da Unidade atende, diariamente, as especialidades de Pediatria, Clínica Médica, Cirurgia Geral, Ortopedia, Cirurgia Vascular e Bucomaxilo; a Emergência recebe as demandas mais graves, das mesmas especialidades atendidas no Serviço de Pronto Atendimento. Todavia, é necessário ressaltar que, em ambos os setores, dependendo da gravidade do caso e após avaliação médica, são gerados atendimentos no centro cirúrgico da Unidade.

Com relação ao Serviço Ambulatorial, pode-se afirmar que este tem caráter pós-cirúrgico e atende as seguintes especialidades: Bucomaxilo, Cirurgia Geral, Cirurgia Vascular, Cirurgia Ortopédica e Terapia Ocupacional.

O cenário atual de crise no setor público da saúde e a grande demanda recebida pelo SUS são problemas que as unidades hospitalares enfrentam diariamente, assim, para manter seus colaboradores motivados, elas precisam buscar estratégias. A Ouvidoria do HMLJ considera que é essencialmente pelo capital intelectual que as organizações podem alcançar resultados positivos e eficazes. Mas como valorizar cada funcionário fazendo com que ele se sinta mais entusiasmado com o seu trabalho?

Todas as organizações, públicas ou privadas, que se preocupam com a valorização dos seus funcionários são mais humanizadas, mais produtivas e possuem colaboradores felizes, satisfeitos e comprometidos com o seu desenvolvimento pessoal e profissional. Os servidores não são números, não são apenas matrículas, eles têm sentimentos, emoções e problemas. Cada um deve ser conhecido e reconhecido na sua essência.

Trabalhador valorizado gera aumento de produtividade e realiza atendimentos mais humanizados, pois se sente parte importante da instituição e apresenta mais comprometimento e prazer em exercer 
sua atividade. O presente trabalho demonstra a importância de valorizar os funcionários no ambiente organizacional e o impacto dessa valorização.

\section{CONCEITO DE VALORES}

Valores são características e particularidades que o sujeito, a sociedade e a organização possuem. São concepções e ideias vistas como importantes e que também influenciam no comportamento da pessoa e no seu modo de pensar.

Os valores representam conceitos e princípios básicos, um modo particular de conduta ou valores finais, que são individual ou socialmente preferíveis a um modo oposto. Eles apresentam um elemento de julgamento baseado naquilo que acreditam ser adequado ou desejável.

Acredita-se que valores são características que as pessoas e as organizações carregam em si. São atitudes e crenças que influenciam o desempenho do ser humano, seu agir e a forma de pensar. Os valores são relevantes no comportamento das organizações, pois é através deles que se tem a percepção do ambiente de trabalho.

Os valores variam de acordo com a percepção de cada indivíduo e têm influência importante no comportamento das pessoas. Só tem valor o que traz algum significado ou que possui importância na vida do indivíduo.

\section{A IMPORTÂNCIA DE VALORIZAR E PRESTIGIAR OS FUNCIONÁRIOS}

Pode-se compreender como valor tudo aquilo que é importante para o ser humano em sua vida pessoal, social ou profissional. As pessoas precisam ser valorizadas e reconhecidas no ambiente profissional por serem os recursos mais importantes de uma instituição.

Quando os funcionários são admirados e reconhecidos, automaticamente se sentem mais envolvidos e comprometidos com a organização, porque se sentem parte essencial dela. É fundamental o gestor valorizar seu colaborador, enfatizando que ele não só faz parte, mas é responsável direto pelo sucesso da organização. São os funcionários que, verdadeiramente, dão vida a uma empresa.

Dessa forma, é de grande importância valorizar cada colaborador, pois é através de seu desempenho que a empresa pode atingir suas metas e alcançar excelentes resultados. Com referência ao ambiente organizacional hospitalar, o funcionário valorizado gera atendimento e prestação de serviços mais humanizados. É importante ressaltar que humanização no SUS é um princípio fundamental para o atendimento de qualidade.

Todo profissional deseja trabalhar em instituições que o valorizem integralmente e que lhe permitam exercer suas potencialidades. Do mesmo modo, a sociedade valoriza as organizações que dão valor às pessoas, e a gestão que atua dessa forma serve de exemplo para outros gestores.

A valorização no ambiente organizacional gera satisfação para toda a equipe de trabalho, melhora o clima e gera aumento na produtividade e, como dito anteriormente, no ambiente do 
SUS, cria um atendimento melhor e humanizado. Valorizar o potencial do colaborador traz grandes impactos positivos em sua vida profissional, melhora seu desempenho e automaticamente sua autoestima.

\section{O TRABALHO DE VALORIZAÇÃO DOS FUNCIONÁRIOS DO HMLJ}

Pensando em uma maneira de destacar o valor dos funcionários de sua unidade hospitalar, a Ouvidoria do Hospital Municipal Lourenço Jorge criou em 2017 a eleição do "Funcionário Padrão" (ver anexo 1).

Seria injusto afirmar que esse trabalho gerou uma onda motivacional no hospital, mais procedente atestar que provocou um "tsunami motivacional".

Além das reclamações, sugestões e denúncias, a Ouvidoria do Hospital Municipal Lourenço Jorge também recebe dezenas de elogios feitos aos funcionários em todas as categorias presentes: administrativos, assistentes sociais, copeiros, dentistas, fisioterapeutas, terapeutas ocupacionais, médicos, técnicos em análises clínicas, técnicos em radiologia, entre outros.

Ao receber os elogios, a Ouvidoria coloca numa planilha excel o nome e a matrícula, em ordem alfabética, dos referidos funcionários. O funcionário mais elogiado no mês ganha o título de "Funcionário Padrão", no período correspondente. A partir daí, são confeccionados dois certificados: um a ser fixado no mural do refeitório da unidade (local de grande circulação diária) e outro para ser entregue ao funcionário homenageado.

Os funcionários testemunham que a premiação os deixa em situação de extrema satisfação e felicidade, pois são parabenizados pela Direção-Geral do hospital e pelos seus colegas de jornada.

Após um ano da implementação dessa ferramenta de valorização, a Ouvidoria do Hospital Municipal Lourenço Jorge pôde afirmar que houve uma redução significativa de $37 \%$ no número total de reclamações dos usuários do Sistema Único de Saúde. Este resultado foi constatado após um estudo comparativo entre os anos 2016 e 2017, visto que essa prática fora em implantada em janeiro de 2017.

Observou-se que em 2016 houve 924 solicitações classificadas como reclamação de usuários. Em contrapartida, em 2017 este número caiu para 582 solicitações de reclamação.

Ainda com base nesse estudo, tendo como referência os períodos de não implementação e de implementação da boa prática, constatou-se que houve um aumento de $43 \%$ das solicitações referentes a elogios a profissionais e a setores da Unidade. Durante todo o ano de 2016, houve 312 atendimentos classificados como elogio aos funcionários e setores. No ano seguinte, a demanda subiu para 446 casos classificados como elogio.

A Ouvidoria HMLJ, após análise dos indicadores, considerou a proposta de valorização do servidor o instrumento necessário para estimular o bom trabalho individual e de equipe, gerando um atendimento mais humanizado e com mais qualidade.

É importante lembrar que tal prática, com todo benefício que proporciona à organização, é um método de trabalho que demanda despesas mínimas, com excelente custo-benefício, gerando resultados edificantes. 
Os funcionários premiados, por realizarem um trabalho de excelência, melhoraram ainda mais seu desempenho, e aqueles que outrora se sentiam desmotivados e sem esperança foram tomados por sentimentos de entusiasmo e inspiração para fazer o melhor.

É importante lembrar que funcionário valorizado significa funcionário satisfeito, e a satisfação pessoal e profissional é apontada como elemento que exerce grande impacto sobre a saúde do trabalhador, em sua qualidade de vida e em seu comportamento.

Assim sendo, a satisfação e a realização no trabalho estão intimamente ligadas à saúde do indivíduo, daí observar-se que pessoas mais satisfeitas com seu trabalho apresentam melhor condição de saúde e menor ocorrência de doenças. A satisfação no trabalho também tem sido apontada como um fator associado à longevidade (FRASER, 1983; LOCKE, 1976; MINISTÉRIO DA SAÚDE, 1999).

\section{PESQUISA DE CLIMA ORGANIZACIONAL}

Outro trabalho desenvolvido e implantado pela Ouvidoria do Hospital Municipal Lourenço Jorge é a PCO - Pesquisa de Clima Organizacional (ver anexo 2).

A Ouvidoria acredita que tão importante quanto, literalmente, ouvir o público externo é ouvir o público interno, ou seja, funcionários e colaboradores.

Numa organização como o Hospital Municipal Lourenço Jorge, com mais de mil funcionários, é necessário um trabalho para analisar e redirecionar possíveis funcionários que, não satisfeitos com o atual setor, possam ser mais produtivos e felizes em outro departamento.

A pesquisa funciona como uma entrevista de $\mathrm{RH}$, porém sem caráter cerimonioso e protocolar.

Por essa pesquisa constata-se que, numa grande organização, não raro há funcionários subaproveitados em funções aquém de sua capacidade profissional e pessoas insatisfeitas que, com um simples redirecionamento, podem se tornar mais realizadas e produtivas.

A pesquisa é composta por 34 questões, que traduzem o nível de satisfação e insatisfação dentro da Unidade.

No item 32, é solicitado ao entrevistado que escolha as duas principais razões pelas quais ele trabalha na empresa. Dos trezentos entrevistados, $86 \%$ declararam como razão principal a estabilidade profissional, $9 \%$ o relacionamento com a chefia e $5 \%$ as respostas restantes.

No item 33, são apurados os três principais fatores que geram mais insatisfação no trabalho, sendo eles: $47 \%$ sobrecarga de trabalho, $28 \%$ baixa remuneração (no campo outros) e $25 \%$ falta de treinamento.

A Pesquisa de Clima Organizacional representa um importante instrumento de gestão, auxiliando os administradores de empresas de pequeno, médio e grande porte.

\section{CONSIDERAÇÕES FINAIS}

Dessa forma, conclui-se que é essencial a organização valorizar seus funcionários no setor de trabalho, porque são eles os responsáveis pelo sucesso final. Quando a organização prioriza valori-

300 | Revista Científica da Associação Brasileira de Ouvidores/Ombudsman - Ano 2 - nº 2 - 2019 
zar os colaboradores, não apenas seus resultados melhoram e aumentam, mas também conquista funcionários comprometidos, envolvidos, respeitosos e satisfeitos com o seu trabalho. Para manter um ambiente saudável é preciso manter uma empresa fortalecida e alicerçada nos devidos valores.

Constata-se que, para que funcionários trabalhem satisfeitos, envolvidos, comprometidos e se sentindo parte da empresa, é necessário reconhecer e valorizar cada sucesso obtido, elogiar cada mérito e conquista alcançada pelo empregado, para que ele produza com mais satisfação e se sinta valorizado por fazer parte da equipe de trabalho.

Por isso, torna-se fundamental valorizar cada potencial no ambiente de trabalho, porque sem pessoas para produzir, inovar, criar ideias e gerar sinergia não há organização.

Por todos esses aspectos, é imprescindível que os gestores valorizem cada colaborador na empresa, porque são eles que dão vida, produtividade e resultados preciosos para a organização. $\mathrm{E}$ não obstante o senso comum acreditar que a Ouvidoria destina-se apenas a ouvir e trabalhar suas demandas, o presente artigo mostra que a Ouvidoria pode e deve ser um poderoso instrumento de gestão organizacional.

\section{REFERÊNCIAS}

BERGAMINI, Cecilia Whitaker. Motivação nas organizações. 5. ed. São Paulo: Atlas, 2008.

CHIAVENATO, Idalberto. Gerenciando com as pessoas: transformando o executivo em um excelente gestor de pessoas. Rio de Janeiro: Elsevier, 2005.

ELTON, C.; GOSTICK, A. O princípio do reconhecimento. Rio de Janeiro: Elsevier, 2009.

FRASER, 1983; LOCKE, 1976; MINISTÉRIO DA SAÚDE, 1999. In: Cadernos de Psicologia Social do Trabalho. v. 6 , 2003.

GARRET, Alexandre; TACHIZAWA, Takeshy. Crenças e valores em nossas organizações. São Paulo: Cultura, 2006.

HUNTER, J. O monge e o executivo. Tradução de M. C. F. de Magalhães. Rio de Janeiro: Sextante, 2004.

KUCZMARSKI, Susan Smith; KUCZMARSKI, Thomas D. Liderança baseada em valores. São Paulo: Educator, 1999. MATOS, Gustavo Gomes de. Comunicação empresarial sem complicação. 2. ed. São Paulo: Manole, 2009.

SIQUEIRA, M. M. M. (Org.). Medidas do comportamento organizacional: ferramentas de diagnóstico e de gestão. Porto Alegre: Artmed, 2008.

\section{ANEXO 1 - MODELO DO CERTIFICADO DE FUNCIONÁRIO DO MÊS}

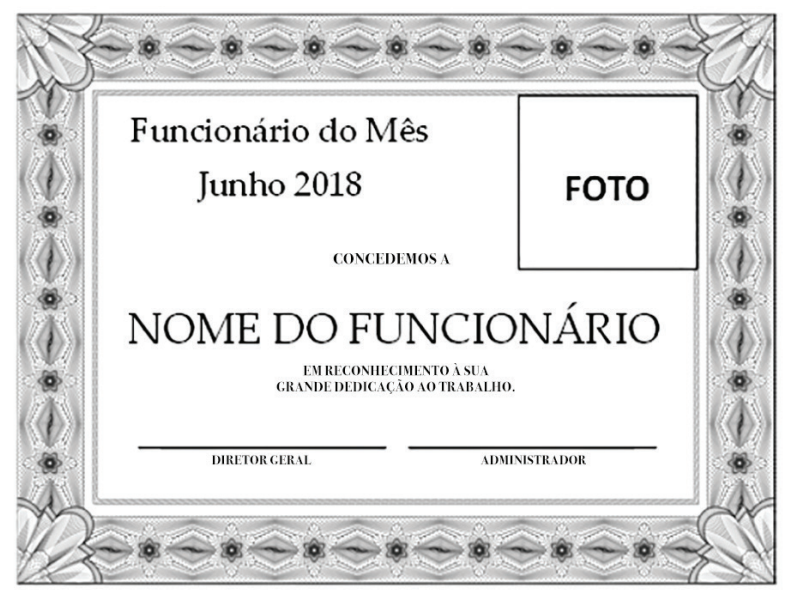




\section{ANEXO 2 - PESQUISA DE CLIMA ORGANIZACIONAL}

01. Considerando sua condição de saúde, como você avalia:

Seu estado físico:

( ) Ótimo ( ) Bom ( ) Razoável ( ) Ruim ( ) Péssimo

Seu estado mental:

( ) Ótimo ( ) Bom ( ) Razoável ( ) Ruim ( ) Péssimo

Seu estado emocional:

( ) Ótimo ( ) Bom ( ) Razoável ( ) Ruim ( ) Péssimo

02. A empresa exige um procedimento rígido para a execução das atividades pertinentes às suas funções?

( ) Sempre ( ) Quase sempre ( ) Raramente ( ) Nunca ( ) Não tenho opinião

03. É você que organiza sua rotina de trabalho para melhor aproveitamento de suas atividades?

( ) Sempre ( ) Quase sempre ( ) Raramente ( ) Nunca ( ) Não tenho opinião

04. Até que ponto você cumpre as responsabilidades que são destinadas à sua função?

( ) Sempre ( ) Quase sempre ( ) Raramente ( ) Nunca ( ) Não tenho opinião

05. Você considera que é sua responsabilidade contribuir para o sucesso da empresa?

( ) Sim ( ) Não ( ) Não tenho opinião

06. Você desempenha seu trabalho buscando obter resultados melhores do que aqueles esperados pela empresa?

( ) Sempre ( ) Quase sempre ( ) Raramente ( ) Nunca ( ) Não tenho opinião

07. Você se considera comprometido com suas atividades?

( ) Sempre ( ) Quase sempre ( ) Raramente ( ) Nunca ( ) Não tenho opinião

08. Você está satisfeito com o seu cargo?

( ) Sim ( ) Não ( ) Mais ou menos

09. O seu trabalho Ihe dá um sentimento de realização profissional?

( ) Sempre ( ) Quase sempre ( ) Raramente ( ) Nunca ( ) Não tenho opinião

10. Você se sente satisfeito em relação ao volume de trabalho que realiza?

( ) Sim ( ) Não ( ) Mais ou menos 
11. Como a direção da empresa se comunica com seus funcionários?

( ) Adequadamente ( ) Razoavelmente ( ) Inadequadamente

12. Os funcionários sentem-se seguros para dizer o que pensam?

( ) Sempre ( ) Quase sempre ( ) Raramente ( ) Nunca ( ) Não tenho opinião

13. A empresa é aberta a receber e reconhecer críticas, opiniões e contribuições de seus funcionários?

( ) Sempre ( ) Quase sempre ( ) Raramente ( ) Nunca ( ) Não tenho opinião

14. As orientações que você recebe sobre o seu trabalho são claras e objetivas?

( ) Sempre ( ) Quase sempre ( ) Raramente ( ) Nunca ( ) Não tenho opinião

15. Você se sente apto para assumir maiores ou mais responsabilidades?

( ) Sim ( ) Não ( ) Mais ou menos

16. Você gostaria de trabalhar em outro departamento da empresa?

( ) $\operatorname{Sim}($ ) Não

17. A empresa oferece oportunidades para o seu desenvolvimento e crescimento profissional?

( ) Sempre ( ) Quase sempre ( ) Raramente ( ) Nunca ( ) Não tenho opinião

18. Você se sente respeitado pelo seu chefe/gestor/gerente?

( ) Sempre ( ) Quase sempre ( ) Raramente ( ) Nunca ( ) Não tenho opinião

19. Você respeita seu chefe/gestor/gerente?

( ) Sempre ( ) Quase sempre ( ) Raramente ( ) Nunca ( ) Não tenho opinião

20. O seu chefe/gestor/gerente é receptivo às sugestões de mudança?

( ) Sempre ( ) Quase sempre ( ) Raramente ( ) Nunca ( ) Não tenho opinião

21. Existe um relacionamento de cooperação entre os departamentos da empresa?

( ) Sim ( ) Não ( ) Não tenho opinião

22. Como você considera o relacionamento entre os funcionários da empresa?

( ) Adequado ( ) Razoável ( ) Inadequado

23. Você se sente valorizado pela empresa?

( ) Sim ( ) Não ( ) Mais ou menos 
24. Você considera que o seu potencial de realização profissional tem sido adequadamente aproveitado?

( ) Sempre ( ) Quase sempre ( ) Raramente ( ) Nunca ( ) Não tenho opinião

25. A empresa reconhece os bons funcionários?

( ) Sempre ( ) Quase sempre ( ) Raramente ( ) Nunca ( ) Não tenho opinião

26. Você recebeu o devido treinamento para a execução de seu cargo?

( ) Sim ( ) Não ( ) Mais ou menos

27. A empresa investe em treinamentos necessários para o desenvolvimento profissional e pessoal de seus funcionários?

( ) Sim ( ) Não ( ) Mais ou menos

28. Considera a empresa um bom lugar para trabalhar?

( ) Sim ( ) Não ( ) Não tenho opinião

29. Você considera a empresa ética com seus funcionários/clientes/ parceiros?

( ) Sempre ( ) Quase sempre ( ) Raramente ( ) Nunca ( ) Não tenho opinião

30. Os assuntos importantes são debatidos em equipe?

( ) Sempre ( ) Quase sempre ( ) Raramente ( ) Nunca ( ) Não tenho opinião

31. A empresa estimula o trabalho em equipe?

( ) Sempre ( ) Quase sempre ( ) Raramente ( ) Nunca ( ) Não tenho opinião

32. Indique as duas principais razões pelas quais você trabalha na empresa.

Coloque número 1 na principal e número 2 na segunda mais importante.

( ) Benefícios oferecidos pela empresa

( ) Estabilidade no emprego

( ) Relacionamento com a chefia

( ) O trabalho que realizo

( ) Ambiente de trabalho

( ) Prestígio da empresa

( ) Autonomia no trabalho

( ) Possibilidade de treinamento

( ) Reconhecimento 
33. Indique três principais fatores que geram mais insatisfação no seu trabalho.

Coloque número 1 no fator que gera mais insatisfação, número 2 no segundo maior fator de insatisfação e o número 3 para o terceiro maior fator de insatisfação.

( ) Falta de reconhecimento

( ) Falta de segurança no emprego

( ) Impossibilidade de crescimento profissional

( ) Falta de autonomia

( ) Ambiente de trabalho ruim

( ) O trabalho que realizo

( ) Relacionamento com a chefia

( ) Falta de treinamento

( ) Sobrecarga de trabalho

( ) Outros:

Que sugestões você daria para tornar a empresa um lugar melhor para se trabalhar? 